\title{
Khatmiamycin, a motility inhibitor and zoosporicide against the grapevine downy mildew pathogen Plasmopara viticola from Streptomyces sp. ANK313
}

\author{
Muna Ali Abdalla ${ }^{1}$, Hnin Yu Win ${ }^{1}$, Md. Tofazzal Islam ${ }^{2,3}$, Andreas von Tiedemann ${ }^{3}$, Anja Schüffler ${ }^{4}$ \\ and Hartmut Laatsch ${ }^{1}$
}

In the course of our screening for anti-peronosporomycetal agents, we isolated a new compound khatmiamycin (1), together with five known metabolites, GTRI-02 (3), 4-ethyl-5-methyl-heptanamide (4), aloesaponarin II (5), LL-C10037 $\alpha$ (6) and LL-C10037 $\beta$ (7) from the culture broth of a terrestrial Streptomyces sp. ANK313. The structures of these metabolites were assigned on the basis of their spectroscopic data. Khatmiamycin (1) exhibited potent motility inhibitory (100\%) and lytic $(83 \pm 7 \%)$ activities against zoospores of the grapevine downy mildew pathogen Plasmopara viticola at $10 \mu \mathrm{g} \mathrm{ml}^{-1}$, followed by compounds 5

(MIC $25 \mu \mathrm{g} \mathrm{ml}^{-1}$ ), 7, 6, 3 in the order of decreasing activity. Khatmiamycin (1) also showed potent antibacterial activity against Staphylococcus aureus and Streptomyces viridochromogenes (Tü57) by causing inhibition zones of 11 and $14 \mathrm{~mm}$ diameter, respectively, at the dose of $40 \mu \mathrm{g}$ per disk. This is the first report on motility inhibitory and lytic activities of metabolites from a terrestrial Streptomyces species against the zoospores of downy mildew pathogen $P$. viticola.

The Journal of Antibiotics (2011) 64, 655-659; doi:10.1038/ja.2011.68; published online 3 August 2011

Keywords: antibacterial; naphthoquinones; oomycetes; Streptomyces; zoosporicide

\section{INTRODUCTION}

Peronosporomycetes are distinct from fungi and are phylogenetic relatives of brown algae and diatoms. They cause many destructive diseases in plants, animals, fishes and humans. ${ }^{1,2}$ One of the most notorious members of peronosporomycetes, Plasmopara viticola, is an obligate biotroph and a serious pathogen of grapevine worldwide. Many fungicides are ineffective against this phytopathogen, and hence, bioactive compounds with new modes of action are needed to combat this economically important pest. Under favorable environmental conditions, the fungus-like stramenopile, $P$. viticola infects grapevine leaves through characteristic biflagellate motile zoospores released from airborne sporangia coming from other infected plants. The zoospores aggregate to stomata of the grapevine leaf by swimming through water film and then rapidly encyst to become round cystospores by shedding their flagella. ${ }^{3,4}$ The cystospores then rapidly germinate to form germ tubes and penetrate host tissue through the stomata. Disruption of any of these asexual stages eliminates the potential for pathogenesis. ${ }^{5}$ The success of any zoosporic pathogen can be attributed in part to the speed of asexual differentiation to generate bi-flagellated motile zoospores and their ability to find a host through chemotaxis. ${ }^{6}$ Therefore, compounds that can interfere with normal swimming behavior and early development of $P$. viticola are supposed to be important as lead compounds in the management of this notorious phytopathogen. ${ }^{4}$

Streptomycetes are known to produce diverse groups of interesting bioactive secondary metabolites. ${ }^{7}$ In the course of screening for secondary metabolites from actinomycetes, we found that the crude extract of a terrestrial Streptomyces sp. ANK313 remarkably inhibited motility of $P$. viticola zoospores and caused subsequent lysis at $100 \mu \mathrm{g} \mathrm{ml}^{-1}$. This observation prompted us to isolate and characterize the motility-inhibitory and lytic factors in the extracts by chromatographic fractionation. We have discovered a new motility inhibitor and zoosporicide named khatmiamycin (1) along with five known compounds from extracts of the culture broth of Streptomyces sp. ANK313. This study describes the isolation, structure elucidation and biological activity of khatmiamycin (1) and further known compounds towards zoospores of Plasmopara viticola.

\section{MATERIALS AND METHODS}

Optical rotation was measured on a Perkin-Elmer polarimeter (model 241) (Perkin-Elmer, San Jose, CA, USA). - NMR spectra were measured on a Varian Inova $600(599.740 \mathrm{MHz})$ and a Varian Unity $300(300.145 \mathrm{MHz})$ spectrometer. - ESI mass spectra were recorded on a Quattro Triple Quadrupol mass spectrometer with a Finnigan TSQ 7000 with nano-ESI API ion source. -

\footnotetext{
${ }^{1}$ Institute of Organic and Biomolecular Chemistry, Georg-August University Göttingen, Göttingen, Germany; ${ }^{2}$ Department of Biotechnology, Bangabandhu Sheikh Mujibur Rahman Agricultural University, Gazipur, Bangladesh; ${ }^{3}$ Department of Crop Sciences, Division of Plant Pathology and Plant Protection, Georg-August-University Göttingen, Göttingen, Germany and ${ }^{4}$ Institute of Biotechnology and Drug Research (IBWF), Kaiserslautern, Germany

Correspondence: Professor H Laatsch, Institute of Organic and Biomolecular Chemistry, University of Goettingen, Tammannstrasse 2, Goettingen D-37077, Germany. E-mail: hlaatsc@gwdg.de

Received 15 December 2010; revised 28 June 2011; accepted 29 June 2011; published online 3 August 2011
} 
HRESI mass spectra were measured on a Micromass LCT mass spectrometer coupled with a HP 1100 HPLC and a diode array detector. Column chromatography was carried out on MN silica gel $60,0.05-0.2 \mathrm{~mm}$; TLC was performed on Polygram SIL G/UV 254 . All silica gel materials were purchased from Macherey-Nagel, Düren, Germany. - Size exclusion chromatography was done on Sephadex LH-20 (Lipophilic Sephadex; Amersham Biosciences, Freiburg, Germany, purchased from Sigma-Aldrich Chemie, Steinheim, Germany). XAD-16 adsorber resin was obtained from Rohm and Haas (Frankfurt, Germany).

\section{Taxonomy of the producing strain}

Streptomyces sp. ANK313 has been derived from a soil sample (Kaiserslautern) and was isolated on YMG agar at room temperature (YMG agar: $2 \mathrm{gl}^{-1}$ yeast extract, $5 \mathrm{gl}^{-1}$ malt extract, $5 \mathrm{gl}^{-1}$ glucose, $15 \mathrm{gl}^{-1}$ agar, $30 \mathrm{mgl}^{-1}$ cycloheximide). Its $16 \mathrm{~S}$ rRNA gene sequence was deposited in GenBank with the Accession Nr. HQ662219. The sequence shows high similarities to Streptomyces ansochromogenes subsp. ansochromogenes strain NBRC 13665 with 99.7\% (GenBank Accession Nr. AB184448), and to Streptomyces achromogenes subsp. streptozoticus strain NBRC 14001 (GenBank Accession Nr. AB184562), as well as to Streptomyces nogalater strain NBRC 13445 (GenBank Accession Nr. AB184408), both with 99.6\% homology. The strain Streptomyces sp. ANK313 is deposited in the culture collection at the Institute of Organic and Biomolecular Chemistry, Göttingen, Germany.

\section{Fermentation, extraction and isolation}

The Streptomyces sp. ANK313 was cultivated on $\mathrm{M}_{2}{ }^{+}$medium for 7 days and extracted with ethyl acetate (mycelium) and XAD-16 resin (filtrate), respectively, as described for related strains. ${ }^{8}$ The combined extracts were chromatographed on silica gel using a $\mathrm{CH}_{2} \mathrm{Cl}_{2} / \mathrm{MeOH}$ gradient $(0-10 \% \mathrm{MeOH})$ to obtain three fractions (Figure 1). On TLC, fraction II showed two yellow components, which were further purified on Sephadex LH-20 followed by PTLC and again Sephadex LH-20 to get three compounds 1 (2.6 mg), $3(5.8 \mathrm{mg})$ and $4(7.0 \mathrm{mg})$. Fraction III was subjected to Sephadex LH-20 using MeOH followed by RP-18 to deliver compounds $5(2.1 \mathrm{mg})$ and $\mathbf{6}(19.5 \mathrm{mg})$. Purification of fraction IV on RP18 followed by PTLC revealed finally compound 7 (9.9 mg); for structures, see Figure 2).

\section{Production of zoospores and bioassay}

Sporangia of P. viticola were isolated from the infected leaves of grapevine (Vitis vinifera cv. Müller-Thurgau) stalk received from Prof Beate Berkelmann, Geisenheim Research Center, Germany. This strain was originally gained from
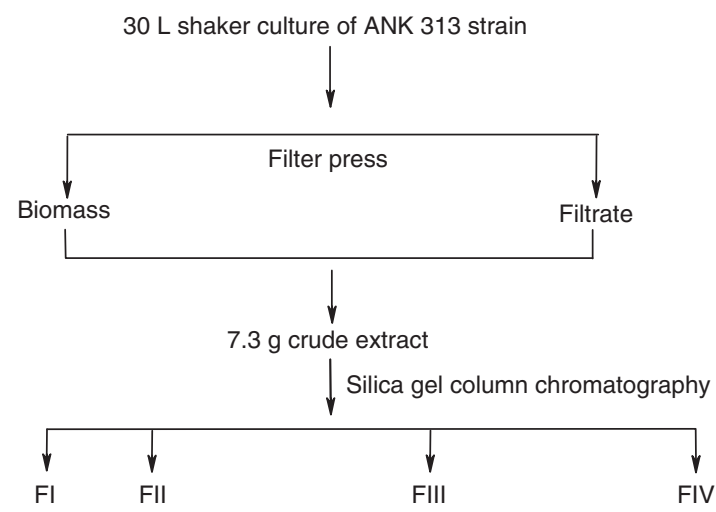

\begin{tabular}{l|l} 
Fat \& fatty acids & $\begin{array}{l}\text { 1. Sephadex LH-20 } \\
\text { MeOH } \\
\text { 2. PTLC } \\
\text { 3. Sephadex LH-20 } \\
\text { MeOH }\end{array}$
\end{tabular}

Khatmiamycin

GTRI-02

Aloesaponarin II

4-Ethyl-5-methylheptanamide

Figure 1 Isolation of khatmiamycin (1) and other metabolites. infected leaf materials of the grapevine cv. Riesling in 1996 and since then always propagated on fresh leaves of Müller-Thurgau. The strain was maintained by regular culturing on the lower surface of young grapevine leaves on Petri dishes containing $1.5 \%$ agar at $25^{\circ} \mathrm{C}$ and $95 \%$ relative humidity. ${ }^{4}$ At day 6 of cultivation, the sporangiophores bearing lemon-shaped sporangia were harvested into an Eppendorf vial by a micro-vacuum cleaner. ${ }^{4}$ The freshly harvested sporangia were separated from sporangiophores by filtration through a nylon sieve $(50 \mu \mathrm{m}$ mesh), washed twice with distilled water and then incubated in sterilized tap water $\left(3 \times 10^{4}\right.$ sporangia per $\left.\mathrm{ml}\right)$ in the dark for $6 \mathrm{~h}$ at room temperature $\left(23^{\circ} \mathrm{C}\right)$ to release zoospores. These zoospores remained motile for $10-12 \mathrm{~h}$ in sterilized water and were used for the bioassay. Stock solutions of crude extracts and pure compounds were first prepared in<smiles>COC(=O)CC(O)C(O)C1=CC(=O)c2c(O)cccc2C1=O</smiles>

1<smiles>O=C1C[C@H](O)[C@H](C2=CC(=O)c3c(O)cccc3C2=O)O1</smiles>

2a: $9 S$

2b: $9 R$<smiles>CCC(C)C(CC)CCC(N)=O</smiles>

4<smiles>CC(=O)NC1=CC(O)[C@H]2O[C@H]2C1=O</smiles>

6<smiles>CC(=O)c1c(O)cc2c(c1C)C(=O)CC(O)C2</smiles><smiles>Cc1cc(O)cc2c1C(=O)c1c(O)cccc1C2=O</smiles>

5<smiles>CC(=O)NC1=C[C@H](O)[C@H](O)CC1=O</smiles>

7
Figure 2 Structures of khatmiamycin (1), juglomycins A and B (2a/b) and other metabolites from Streptomyces sp. ANK313.

\section{Table 1 Physico-chemical properties of 1}

\begin{tabular}{ll}
\hline Appearance & Yellow solid \\
Molecular formula & $\mathrm{C}_{15} \mathrm{H}_{14} \mathrm{O}_{7}$ \\
$(+)$-ESI MS $(\mathrm{m} / \mathrm{z})$ & $329(\mathrm{M}+\mathrm{Na})^{+}$ \\
$R_{f}$ value on TLC & $0.49^{\mathrm{a}}$ \\
{$[\alpha]_{D}^{20}$} & $-21^{\circ}\left(\mathrm{c} \mathrm{O} .1, \mathrm{CH}_{3} \mathrm{OH}\right)$ \\
UV/VIS: $\lambda_{\max }(\log \varepsilon)$, & $243(4.11), 265(4.02)$, \\
$(\mathrm{MeOH})$ & $322(3.51), 412(3.38)$ \\
Solubility & $\mathrm{CH}_{2} \mathrm{Cl}_{2}, \mathrm{MeOH}, \mathrm{DMSO}$
\end{tabular}

${ }^{\mathrm{a}} \mathrm{CH}_{2} \mathrm{Cl}_{2} / \mathrm{MeOH}$ (95:5). 
Table $2{ }^{13} \mathrm{C}(125 \mathrm{MHz})$ and ${ }^{1} \mathrm{H}(300 \mathrm{MHz})$ NMR data of khatmiamycin (1) in $\mathrm{CD}_{2} \mathrm{Cl}_{2}$; weak $\mathrm{HMBC}$ correlations are included in brackets

\begin{tabular}{|c|c|c|c|}
\hline No. & $\delta_{C}$ & $\delta_{H}($ mult.; J in $H z)$ & Selected HMBC correlations \\
\hline 1 & 184.5 & & \\
\hline 2 & 150.9 & & \\
\hline 3 & 135.4 & $7.04(d, J=1.4)$ & C-1, C-2, C-4a, (C-5), C-9 \\
\hline 4 & 190.3 & & \\
\hline $4 a$ & 115.2 & & \\
\hline 5 & 161.5 & & \\
\hline 6 & 124.6 & $7.27(\mathrm{dd}, J=7.7,1.9)$ & C-4a, C-8 \\
\hline 7 & 136.6 & $7.64(\mathrm{t}, J=7.9)$ & C-5, C-8a \\
\hline 8 & 119.3 & $7.62(\mathrm{dd}, J=7.9,2.5)$ & C-1, C-4a, C-6 \\
\hline $8 a$ & 132.4 & & \\
\hline 9 & 70.6 & $4.79(\mathrm{~s}, \mathrm{br})$ & $(C-2), C-3$ \\
\hline 10 & 69.6 & $4.21(\mathrm{~m})$ & \\
\hline 11 & 38.6 & $\begin{array}{l}2.78(\mathrm{ABX}, J=16.6,8.4,) \\
2.66(1 \mathrm{H}, \mathrm{ABX}, J=16.6,3.9,)\end{array}$ & C-10, C-12 \\
\hline 12 & 173.1 & & \\
\hline OMe & 52.3 & 3.69 (s) & (C-11), C-12, \\
\hline $\mathrm{OH}$ & - & $11.82(\mathrm{~s})$ & $C-4 a, 5,6,(7)$ \\
\hline
\end{tabular}

dimethyl sulfoxide (DMSO) and then diluted with distilled water. The concentration of DMSO in the zoospore suspension never exceeded $1 \%(\mathrm{v} / \mathrm{v})$, a condition that does not affect zoospore motility. The bioassay was carried out as described earlier. ${ }^{5,9}$ Briefly, $40 \mu \mathrm{l}$ of sample suspension was directly added to $360 \mu \mathrm{l}$ of zoospore suspension (ca. $10^{5}$ per ml) taken in a dish of plant tissue culture multi-well plate to make a final volume of $400 \mu \mathrm{l}$ and then quickly mixed with a glass rod; $1 \%$ aqueous DMSO was used as a control. The motility of zoospores was observed under a light microscope at 10-fold magnification. Quantification of time-course changes of motility and lysis of zoospores were carried out as described earlier. ${ }^{4}$ Each treatment was replicated thrice. The mean value $(\%) \pm$ s.e. (standard error) of the affected spores in each treatment was calculated.

\section{RESULTS AND DISCUSSION}

Compound 1 was isolated as yellow solid (Table 1); it showed UV absorption at $254 \mathrm{~nm}$, turned to black with anisaldehyde/sulfuric acid and became blue with $2 \mathrm{~N} \mathrm{NaOH}$ on TLC, indicating a peri-hydroxyquinone.

The ${ }^{1} \mathrm{H}$ NMR spectrum of $\mathbf{1}$ displayed an aromatic ABC system for three adjacent protons (see Supplementary Figure S1). In addition, there was a further narrow doublet at $\delta 7.04(J=1.4 \mathrm{~Hz})$. In the aliphatic region, the spectrum showed two oxygen-bound protons by signals at $\delta 4.79$ and 4.21, a methoxy signal at $\delta 3.69$ and diastereotopic methylene protons at $\delta 2.78$ and 2.66. In the ${ }^{13} \mathrm{C}$ NMR (see Supplementary Figure S2) and HSQC spectra, there were 15 carbon signals as indicated by the HR ESIMS-derived formula $\mathrm{C}_{15} \mathrm{H}_{14} \mathrm{O}_{7}$. Two ketone carbonyl groups at $\delta 190.3$ and 184.5, one carbonyl of an acid or ester at $\delta$ 173.1, eight $\mathrm{sp}^{2}$ carbons (four quaternary and four methine carbons) and four $\mathrm{sp}^{3}$ carbons (two oxygenated $\mathrm{CH}$, one $\mathrm{OCH}_{3}$ and one $\mathrm{CH}_{2}$ ) completed the spectrum (Table 2).

The HMBC spectrum showed correlations from $\mathrm{H}-7$ to $\mathrm{C}-5$ and $\mathrm{C}-8 \mathrm{a}$, the former one (C-5) could be linked to oxygen, from $\mathrm{H}-8$ to C-1 (184.5, CO), C-6 and C-4a, from H-6 to C-8 and C-4a. Furthermore, H-3 showed couplings with C-1 (CO), C-2, C-4a and C-9 of fragment II. H-11 and the methoxy group showed correlations with the carbonyl of an ester at $\delta 173.1$ (C-12). According to the above spectroscopic data, a partial structure (Figure 3 ) with seven of the nine double-bond equivalents can be drawn.

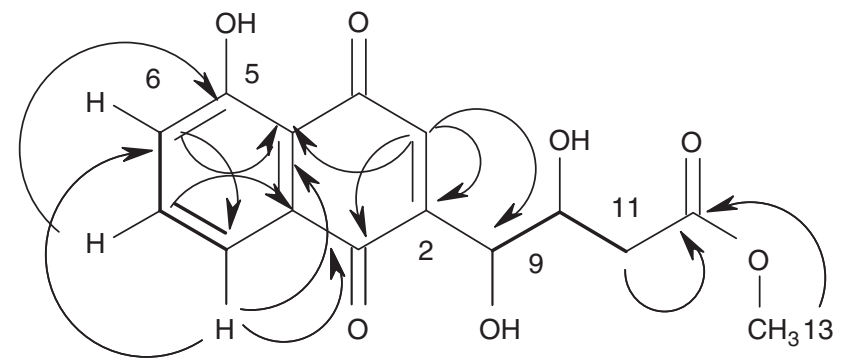

Figure 3 Selected $\mathrm{H}, \mathrm{H}$ COSY (bold bonds) and HMBC correlations (arrows) of khatmiamycin (1).

The remaining ketone carbonyl at $\delta 190.3$ showed no correlations. Placing this carbonyl at C-4 and closing the ring for the remaining double-bond equivalent completes structure $\mathbf{1}$.

Numerous quinone derivatives have been isolated from Streptomyces spp. and fungi. Most heptaketides among them are having an additional annellated ring, forming anthraquinones or naphthopyranequinones, whereas compound 1 bears an open chain. Closely related with $\mathbf{1}$ are the juglomycins ${ }^{10} \mathrm{~A}(\mathbf{2} \mathbf{a})$ and $\mathrm{B}(\mathbf{2} \mathbf{b})$ and the juglone derivative NHAB. ${ }^{11}$

Five further metabolites were identified as GTRI-02 (3), ${ }^{12}$ 4-ethyl-5methyl-heptanamide (4), ${ }^{13}$ aloesaponarin II (5), ${ }^{14}$ LL-C10037 $\alpha(6),{ }^{15}$ and LL-C10037 $\beta(7)^{16}$ by means of AntiBase and comparison of their data with the literature.

Motility inhibitory and lytic activities of khatmiamycin and other metabolites against $P$. viticola zoospores

The motility inhibitory and zoosporicidal activities of khatmiamycin (1) and the other metabolites of Streptomyces sp. ANK313 against downy mildew pathogen $P$. viticola are summarized in Table 3 and Figure 4 . The motility of $P$. viticola zoospores was remarkably inhibited by 1 and 3-7 at low doses. Among the tested compounds, the highest motility inhibitory and lytic activities were recorded for compound 1 (MIC, $10 \mu \mathrm{g} \mathrm{ml}^{-1}$ ) followed by compound 5 (MIC, $25 \mu \mathrm{g} \mathrm{ml}^{-1}$ ). Other three compounds (3,6 and 7) showed almost equal strength of motility inhibitory and lytic activities against zoospores at $50 \mu \mathrm{g} \mathrm{ml}^{-1}$.

Microscopic observation revealed that the crude extract and isolated metabolites showed zoosporicidal activity against $P$. viticola almost in a similar manner: initially, the zoospores were halted and the cellular materials gradually fragmented and dispersed into the surrounding water medium by bursting cell membranes. Motility inhibition and subsequent lysis of zoospores of the sugar beet damping-off pathogen Aphanomyces cochlioides by various kinds of natural products such as polyflavonoid tannins from the bark of Lannea coromandelica, ${ }^{9}$ anacardic acids from Ginkgo biloba, ${ }^{17}$ saponins from Panax notoginseng and macrocyclic lactam antibiotics from Lysobacter sp. SB-K88 have been published. This is the first report on motility inhibition and lysis of zoospores of the downy mildew pathogen $P$. viticola by secondary metabolites from a terrestrial Streptomyces species. Motility of zoospores has been found critical for disease cycle and also virulence of the peronosporomycete phytopathogens. ${ }^{3,18}$ Our observation indicated that Streptomyces spp. produce potent new secondary metabolites, which might be useful for biorational and sustainable management of the peronosporomycete phytopathogens. Therefore, further studies on isolation of more zoospore regulating principles from other Streptomyces spp. may result in interesting metabolites or lead compounds with novel modes of action for developing 
Table 3 Motility inhibitory and lytic activities of compounds isolated from Streptomyces sp. ANK 313 against the zoospores of grapevine downy mildew pathogen Plasmopara viticola

Motility inhibitory and lytic activity $(\% \pm \text { s.e. })^{\text {a }}$ against Plasmopara viticola zoospores

\begin{tabular}{|c|c|c|c|c|c|c|c|c|c|}
\hline \multirow[b]{2}{*}{ Compound } & \multirow[b]{2}{*}{ Dose $\left(\mu g m I^{-1}\right)$} & \multicolumn{2}{|l|}{$15 \min$} & \multicolumn{2}{|l|}{$30 \min$} & \multicolumn{2}{|l|}{$45 \min$} & \multicolumn{2}{|l|}{$60 \mathrm{~min}$} \\
\hline & & Motility inhibition & Lysis & Motility inhibition & Lysis & Motility inhibition & Lysis & Motility inhibition & Lysis \\
\hline \multirow[t]{4}{*}{1} & 5 & $0 \pm 0$ & $0 \pm 0$ & $0 \pm 0$ & $0 \pm 0$ & $0 \pm 0$ & $0 \pm 0$ & $0 \pm 0$ & $0 \pm 0$ \\
\hline & 10 & $0 \pm 0$ & $0 \pm 0$ & $55 \pm 7$ & $38 \pm 3$ & $78 \pm 8$ & $48 \pm 5$ & $100 \pm 0$ & $83 \pm 7$ \\
\hline & 25 & $73 \pm 7$ & $47 \pm 6$ & $97 \pm 2$ & $77 \pm 5$ & $100 \pm 0$ & $87 \pm 8$ & $100 \pm 0$ & $99 \pm 1$ \\
\hline & 50 & $100 \pm 0$ & $100 \pm 0$ & $\mathrm{nt}$ & $\mathrm{nt}$ & nt & $\mathrm{nt}$ & $\mathrm{nt}$ & $\mathrm{nt}$ \\
\hline \multirow[t]{3}{*}{3} & 10 & $0 \pm 0$ & $0 \pm 0$ & $0 \pm 0$ & $0 \pm 0$ & $0 \pm 0$ & $0 \pm 0$ & $0 \pm 0$ & $0 \pm 0$ \\
\hline & 25 & $0 \pm 0$ & $0 \pm 0$ & $15 \pm 4$ & $0 \pm 0$ & $35 \pm 3$ & $0 \pm 0$ & $45 \pm 7$ & $0 \pm 0$ \\
\hline & 50 & $47 \pm 5$ & $30 \pm 6$ & $100 \pm 0$ & $100 \pm 0$ & nt & nt & nt & nt \\
\hline \multirow[t]{3}{*}{5} & 10 & $0 \pm 0$ & $0 \pm 0$ & $0 \pm 0$ & $0 \pm 0$ & $0 \pm 0$ & $0 \pm 0$ & $0 \pm 0$ & $0 \pm 0$ \\
\hline & 25 & $41 \pm 7$ & $0 \pm 0$ & $90 \pm 8$ & $51 \pm 5$ & $93 \pm 6$ & $69 \pm 7$ & $100 \pm 0$ & $88 \pm 5$ \\
\hline & 50 & $88 \pm 5$ & $31 \pm 7$ & $100 \pm 0$ & $95 \pm 3$ & $100 \pm 0$ & $98 \pm 3$ & $100 \pm 0$ & $100 \pm 0$ \\
\hline \multirow[t]{3}{*}{6} & 10 & $0 \pm 0$ & $0 \pm 0$ & $0 \pm 0$ & $0 \pm 0$ & $0 \pm 0$ & $0 \pm 0$ & $0 \pm 0$ & $0 \pm 0$ \\
\hline & 25 & $0 \pm 0$ & $0 \pm 0$ & $0 \pm 0$ & $0 \pm 0$ & $19 \pm 5$ & $0 \pm 0$ & $52 \pm 6$ & $0 \pm 0$ \\
\hline & 50 & $49 \pm 5$ & $21 \pm 3$ & $100 \pm 0$ & $100 \pm 0$ & $\mathrm{nt}$ & $\mathrm{nt}$ & $\mathrm{nt}$ & $\mathrm{nt}$ \\
\hline \multirow[t]{2}{*}{7} & 25 & $0 \pm 0$ & $0 \pm 0$ & $0 \pm 0$ & $0 \pm 0$ & $0 \pm 0$ & $0 \pm 0$ & $0 \pm 0$ & $0 \pm 0$ \\
\hline & 50 & $30 \pm 3$ & $0 \pm 0$ & $59 \pm 7$ & $33 \pm 2$ & $78 \pm 9$ & $49 \pm 5$ & $81 \pm 8$ & $51 \pm 3$ \\
\hline
\end{tabular}

${ }^{a}$ Data presented here are average value \pm s.e. of at least three replications in each dose of test compound.

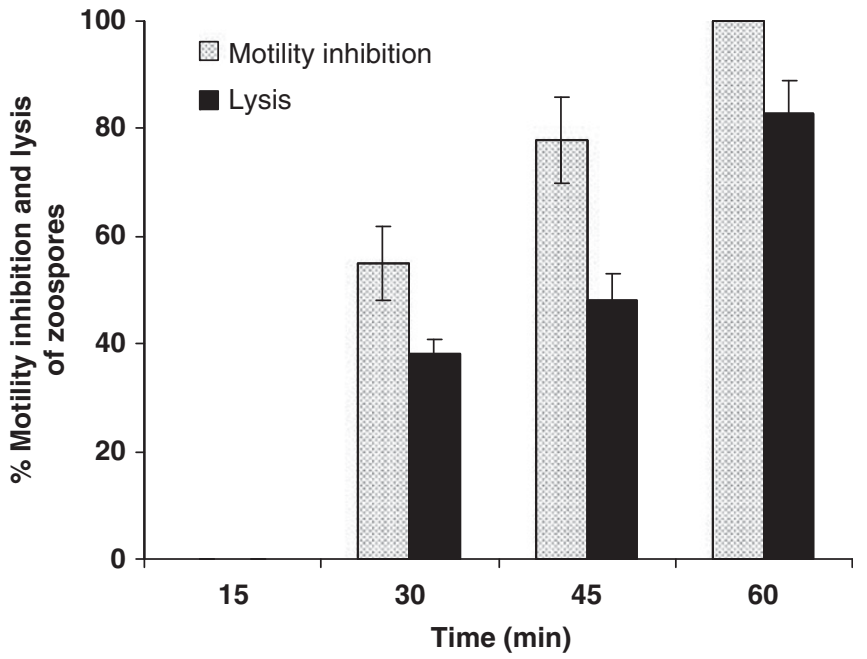

Figure 4 Motility inhibition and lysis activity of khatmiamycin (1) at $10 \mu \mathrm{g} \mathrm{ml}^{-1}$ (ca. $30 \mu \mathrm{m}$ ) against zoospores of the grapevine downy mildew pathogen Plasmopara viticola.

effective control strategy against notorious peronosporomycete phytopathogens.

Khatmiamycin (1) also showed potent antibacterial activity against Staphylococcus aureus and Streptomyces viridochromogenes (Tü57) by causing growth inhibition zones 11 and $14 \mathrm{~mm}$, respectively at the dose of $40 \mu \mathrm{g}$ per paper disk. Khatmiamycin (1) belongs to the group of juglone derivatives, which are known to be cytotoxic ${ }^{19}$ or to show activity against methicillin-resistant staphylococcal strains. ${ }^{20}$ In previous reports GTRI-02 (3) was found to be a lipid peroxidation inhibitor, ${ }^{13}$ and LL-C10037 $\alpha$ (6) exhibited antitumor activity. In our cytotoxicity tests using brine shrimps, 1 was, however, with $10 \%$ mortality at $10 \mu \mathrm{g} \mathrm{ml}^{-1}$ nearly inactive.

\section{CONCLUSION}

In this study, we isolated and characterized the new metabolite khatmiamycin (1), which showed strong motility-inhibitory and lytic effects against the zoospores of a phytopathogenic peronosporomycete $P$. viticola. This metabolite could be useful for protecting grapevine plants from the attack of downy mildew pathogen. Khatmiamycin (1) also exhibited potent antibacterial activity against Staphylococcus aureus and Streptomyces viridochromogenes (Tü 57). Further studies on the zoosporicidal mode of action of these potential zoospore-regulating compounds and their effects on other phytopathogenic peronosporomycetes are needed for considering their practical use as a naturally occurring peronosporomicidal agent.

\section{ACKNOWLEDGEMENTS}

We thank Dr H Frauendorf and R Machinek for the mass and NMR spectra, M Becker, A Kohl and F Lissy for technical assistance, the German Academic Exchange Service (DAAD) for the financial support of MAA \& HYW by PhD grants, and the Alexander von Humboldt Foundation, Germany, for a fellowship to MTI. Sincere thanks are also due to Professor Beate Berkelmann, Geisenheim Research Center, Germany for kindly donating the Plasmopara viticola strain.

1 Islam, Md. T. \& Tahara, S. Chemotaxis of fungal zoospores, with special reference to Aphanomyces cochlioides. Biosci. Biotechnol. Biochem. 65, 1933-1948 (2001).

2 Dick, M. W. The Peronosporomycetes. In The Mycota VII, Part A, Systematics and Evolution (eds McLaughlin, D. J., McLaughlin, E. G. \& Lemke, P. A. ) 39-72 (SpringerVerlag, Berlin, Heidelberg, 2001).

3 Kiefer, B., Riemann, M., Kassemeyer, C. B. H. \& Nick, P. The host guides morphogenesis and stomatal targeting in the grapevine pathogen Plasmopara viticola. Planta Med. 215, 387-393 (2002).

4 Islam, M. T. \& Tiedemann, A. V. Zoosporogenesis and differentiation of grapevine downy mildew pathogen Plasmopara viticola in host-free system. Phytopathology 98, S72 (2008).

5 Islam, M. T., Hashidoko, Y., Deora, A., Ito, T. \& Tahara, S. Suppression of damping-off disease in host plants by the rhizoplane bacterium Lysobacter sp. strain SB-K88 is linked to plant colonization and antibiosis against soilborne Peronosporomycetes. Appl. Environ. Microb. 71, 3786-3796 (2005). 
6 Judelson, H. S. \& Blanco, F. A. The spores of Phytophthora: weapons of plant destroyer. Nat. Rev. Microbiol. 3, 47-58 (2005).

7 Blunt, J. W. et al. Marine natural products. Nat. Prod. Rep. 26, 170-244 (2009).

8 Rahman, H. et al. An imidazopyridinone and further metabolites from Streptomycetes. Nat. Prod. Commun. 4, 965-970 (2009).

9 Islam, M. T., Ito, T., Sakasal, M. \& Tahara, S. Zoosporicidal activity of polyflavonoid tannin identified in Lannea coromandelica stem bark against phytopathogenic oomycete Aphanomyces cochlioides. J. Agric. Food Chem. 50, 6697-6703 (2002).

10 Krupa, J., Lackner, H., Jones, P. G., Schmidt-Bäse, K. \& Sheldrick, G. M. Die absolute Konfiguration der Juglomycine. Z. Naturforsch. 44b, 345-352 (1989).

11 Ozawa, M. et al. Structure and biosynthetic implication of (S)-NHAB, a novel shunt product, from a disruptant of the actVI-ORFA gene for actinorhodin biosynthesis in Streptomyces coelicolor A3(2). Tetrahedron 59, 8793-8798 (2003).

12 Yeo, W. H. et al. GTRI-02, a new lipid peroxidation inhibitor from Micromonospora sp. SA246. J. Antibiot. 51, 952-953 (1998).

13 Valery, M., Dembitsky, I. S. \& Rozentsvet, 0. A. Fatty acid amides from freshwater green alga Rhizoclonium hieroglyphicum. Phytochemistry 54, 965-967 (2000).
14 Yagi, A., Makino, K. \& Nishioka, I. Studies on the constituents of Aloe saponaria HAW. I. the structures of tetrahydroanthracene derivatives and the related anthraquinones. Chem. Pharm. Bull. 22, 1159-1166 (1974).

15 Wipf, P. \& Kim, Y. Synthesis of the antitumor antibiotic LL-C10037.alpha. J. Org. Chem. 59, 3518-3519 (1994).

16 Shen, B., Whittle, Y. G., Gould, S. J. \& Keszler, D. A. Structure and absolute stereochemistry of the epoxyquinol LL-C10037.alpha and related metabolites from Streptomyces LL-C10037. J. Org. Chem. 55, 4422-4426 (1990).

17 Begum, P., Hashidoko, Y., Islam, M. T. \& Tahara, S. Zoosporicidal activity of anacardic acids against Aphanomyces cochlioides. Z. Naturforsch. 57c, 874-882 (2002).

18 Latijnhouwers, M., Ligterink, W., Vleeshouwers, V. G. A. A., van West, P. \& Govers, F. A. G-alpha subunit controls zoospore motility and virulence in the potato late blight pathogen Phytophthora infestans. Mol. Microbiol. 51, 925-936 (2004).

19 Celso, A. C. et al. Molluscicidal activity of 2-hydroxy-[1,4]naphthoquinone and derivatives. An. Acad. Brasil. Ciênc. 80, 329-334 (2008).

20 Pereira, E. M. et al. Tabebuia avellanedae naphthoquinones: activity against methicillin-resistant staphylococcal strains, cytotoxic activity and in vivo dermal irritability analysis. Ann. Clin. Microbiol. Antimicrob. 5, 5 (2006).

Supplementary Information accompanies the paper on The Journal of Antibiotics website (http://www.nature.com/ja) 